\title{
Study on Knowledge Integration in Innovation Clustering Project
}

\author{
Miao Yu, Fangwei Zhu, Peng Wang \\ Faculty of Management and Economics, Dalian University of Technology, Dalian, China \\ Email: key90@mail.dlut.edu.cn, zhufw@dlut.edu.cn,247294777@qq.com
}

How to cite this paper: Yu, M., Zhu, F.W. and Wang, P. (2016) Study on Knowledge Integration in Innovation Clustering Project. Open Journal of Social Sciences, 4, 177-186. http://dx.doi.org/10.4236/jss.2016.411014

Received: November 3, 2016 Accepted: November 25, 2016 Published: November 28, 2016

Copyright $\odot 2016$ by authors and Scientific Research Publishing Inc. This work is licensed under the Creative Commons Attribution International License (CC BY 4.0).

http://creativecommons.org/licenses/by/4.0/ (c) (i) Open Access

\begin{abstract}
In this paper, we establish a framework for analyzing knowledge integration across organizations in the context of innovation clustering. In order to pinpoint the process of national innovation clustering and the internal process of knowledge integration, we view innovation clustering project from a systematic perspective. Based on multiple case studies of typical innovation clustering projects, this study identified multi-dimensional innovation clustering capacity of dominant firm, and established process model of innovation clustering involving innovation capability and knowledge integration. The results show that the perfect matching of innovation clustering capacity and the process of knowledge integration in the whole life cycle of innovation clustering is the key to innovation performance, and the dominant firm centered national innovation system needs the synergy of innovation clustering capability of dominant firm and efficient process of knowledge integration to integrate resources of all subjects and enhance innovative capability of whole system.
\end{abstract}

\section{Keywords}

Knowledge Integration, Innovation Clustering, Innovation Clustering Capability, Cross-Organizational Project

\section{Introduction}

In the export-oriented model of economic development, the growth of China's economy relies mainly on investment and export-led. The independent innovation capability remains weak and industrial resource distribution is still discordant. How to achieve development strategy of innovation-driven has become the core problem in in-depth transformation of Chinese economy. To explain the systematic innovation effect, it is necessary to carry out researches focusing on innovation clustering in the context of the implementation of "National Innovation Strategy". Based on the consideration of over- 
all situation and key element of national innovation system, dominant firm is the conductor of national innovation. Therefore, this paper explored the innovation clustering and knowledge integration process of dominant firm with innovative mega-projects case study and established a process model of innovation clustering. The article is organized as follows. The second section provides the theoretical and conceptual background about innovation clustering and knowledge integration. The third section introduces the methodology of this study and the fourth section elaborates the findings of the multiple case study and discusses how knowledge integration operates in national innovation clustering. The final section concludes and reflects on some directions for further research.

\section{Theoretical Review}

\subsection{Innovation Clustering}

Discontinuity of external technical paradigm, process of technology accumulation, internal economies of scope, innovative induction mechanism and innovation transaction costs drive innovation clustering [1]. Organisation for Economic Co-operation and Development (OECD) formally put forward that innovation clustering is the production network of enterprises which highly interrelated with each other in value-added production chain [2]. Innovation clustering gather more inclines to process then innovation cluster, which reflect the technological trajectory of research activities in innovation cooperation process [3]. Compared with general innovation network [4] [5], the innovation subject in innovation clustering will form a temporary innovation network focusing on temporary specific goal, which is product and process oriented. The typical innovation clustering subject is the national innovation system, which is a network among national departments and institutions [6]. It will facilitate national economic development through interaction and connection between each subject in complex innovation system [7] [8]. The innovation clustering based on national innovation system highlights the efficient allocation of innovation resources and diffusion of innovation effect in a national range [9], which need more cooperation and mechanisms to foster innovation network.

Because of the difference in innovation resource inventory, the advantage of social capital in networks and resource integration capability, dominant firm become a core element in innovation clustering [10]. Dominant firm needs to act as manager and promoter of cross-border innovation activities, the integrator of innovation resources and principal part of innovation pervasion. The effect of innovation clustering is not manifest as the performance of dominant firm, but the innovation performance of whole innovation clustering network. In general innovation networks, the capability of dominant firm such as technology innovation capability, earnings and distribution capabilities, partner selection capabilities, network capabilities and decision-making capabilities [11] [12] are important factors affecting innovation performance. Based on the Uniqueness of innovation clustering, it is necessary to identify the capability of dominant firm in national innovation system and explore its role in innovation clustering. 


\subsection{Knowledge Integration}

Researches related to knowledge integration first appeared in the context of new product development [13] [14]. Henderson and Clark first expressed the concept of knowledge integration and put forward two types knowledge-component knowledge and architectural knowledge. They assumed the process of component knowledge transform to architectural knowledge in specific solutions is knowledge integration. In the view of innovation, the results of knowledge integration are forming new knowledge which is crucial to innovation [15]. Innovation is a problem-solving process [16] and a process of knowledge searching and using [17] as well as knowledge creation and development [18] [19]. The development of information technology and knowledge complexity accelerates the innovation process based on external and internal knowledge integration in interactive innovation network [20] [21]. Innovation clustering among heterogeneous innovative subjects as a systematic innovation process aims at accessing to reorganizational knowledge and integrating discrete knowledge to promoting overall innovation. In essence, innovation clustering is a process of integrating innovation resources and knowledge, in which innovation knowledge will be created, acquired, changed, shared, developed and refined [22]. Therefore, we also need to explain innovation clustering of national innovation system with the systematic knowledge integration process.

\section{Methodology}

We use case study to explore the innovation clustering process of national innovation system subjects. Case study is a research methodology to answer "how" and "why" well, which will explain the effect path between each construct in special context well too [23] [24]. Three dominant firms in China were involved in the case study to investigating the innovation clustering process and its knowledge integration process. They are China Aerospace Science and Technology Group (referred to as "CASC"), China Mobile Communications Corporation (referred to as "CMCC") and China South Locomotive Group (referred to as "CSR"). All these three companies have the common characteristics that they are the leaders from important industries of China, which have typical representativeness.

To ensure the reliability of research, this study use data triangulation and the case investigator triangulation in data collection. Data sources included semi-structured interviews, documentations and observations. The semi-structured interviews were the main source of data. We focus on a mega-project that the dominant firm organized and other departments and organizations participated. Interviewees are all from those projects and are the core leaders. For each project, interviewees are all core leaders of project team members in the innovation clustering network, a total of 10 people were investigated. 20 person-time total interviews were conducted, and each interview lasted between 30 to 60 minutes. After all semi-structured interviews, this study obtained a relatively rich research data. On the other hand, we got plenty of documents and reports about these projects in the interview process, which provides large amount of 
qualitative data. Based on the interview and documents from company and internet, the innovation clustering process was identified and prepared for depth analysis.

\section{Findings and Discussion}

\subsection{Case Background}

CASC is a giant state-owned high-tech companies as the leader of Chinese aerospace science and technology industry. The manned space flight project is a typical innovation clustering practice of CASC. National Manned space project was established officially in 1992 as one of China's long-term major S\&T projects. CASC and CASIC (China Aerospace Science and Industry Corporation) are the dominant firm of this project. Derived by innovation effects spill over, national incentive policies and advantage of resource mobilisation capability of CASC, this project established a resourceful innovation clustering network, innovation subjects only participated in spaceship androcket sub-system are more than 200. After forming innovation clustering networks, CASC has been acting as a backbone organizing overall layout planning, designing the overall scheme design and formulating system management scheme. On the one hand, CASC is directly responsible for the core part- $\mathrm{R} \& \mathrm{D}$ of the spacecraft system and rocket system-and implement tasks based its internal management system of innovation resources. On the other hand, CASC formed strategic planning system, procedure management system, organizing system and opening cooperation system for the project to coordinating and organizing innovation activities of other innovation clustering subjects, which facilitated the exchange of innovation information across organizations and domain, promoted milieux of innovation and integration. In the part of innovation diffusion management and terminal innovation achievements management, CASC promoted the diffusion in the project life cycle, enhanced the innovation ability and earnings of all subjects, and mobilized the development of related industry. Advanced technology created in project also transferred to traditional industries, basic science and technology research institutes.

CMCC is a mobile communications operator established in 2000 in the context of the national telecommunications system reform and is the best in the world on customer network and scale recent years. The typical innovation clustering case in CMCC is the TD-LTE project, which is the most important project in national S\&T projects on "New Wireless Mobile Communications Network". Because of limited technological resources, CMCC choose to use its integration advantages of resources to promoting the establishment of a platform of project cooperation innovation. The project involves lots of representative enterprises in industry chains such as Huawei and Datang Telecom, plenty of domestic research institute such as Tsinghua University and R\&D institute from international frontier, all subjects were integrated to implement this project. At the beginning, CMCC proposed technology needs of multi levels, overall technical ideas, programs and R \& D plan targeted at the technical strategic objectives of the project, and launched a series of technical preparation and construction preparation relying on its multi-level technical innovation organization system. CMCC also established 
a technovation close-loop management mode to enhance the connection between all subjects and facilitate the TD-LTE technology standard synchronization, product synchronization, test synchronization and commercial synchronization. For the innovative products, CMCC strategically combined 27 international telecom operators and equipment manufacturers, submitted TD-LTE innovations to the 3GPP (3G partnership project) organization and formed a universal standard. The success of the project not only escalated the technical knowledge system of CMCC, also guaranteed the innovation efficiency of whole network and diffused to whole innovation system and other telecommunications operators.

CSR is a large state-owned transportation equipment manufacturing enterprises, who has the largest electric locomotive $\mathrm{R} \& \mathrm{D}$ and manufacturing base in the world. The successful development of a new generation of high speed train set CRH380A is a typical cross-organizational innovation cluster. CRH380A project was initiated in the context that establishment of domestic railway equipment design manufacturing system, which relying on key enterprises and supporting enterprises. Based on the advantage of technology import, CSR using its four national research institutions and Sifang Company as the main body of the project united 500 supporting enterprises and more than 100 universities and research institutes to form innovation cluster. Relying on the experience of digestion, absorption and re-innovation, CSR deeply analysed the external technology of high speed EMU and formed national design and manufacturing technical standard system. CSR has carried out 9 key innovation projects directly, and also introduced new project management mechanism and promoted effective process management and innovation management of the project through its design, manufacture and product platforms. They facilitated the standard project and company resources sharing and project knowledge management through the standardization of information system, and enhanced the innovation ability of supplier development through innovation network access, cultivation, evaluation, collaborative innovation system. CRH380A project finished the transformation from the introduction of technology to the independent innovation. The innovation results on patens and standards in high-speed EMU field not only enhanced the core competitiveness of CSR, but also drove innovation of innovation cluster and promoted innovation outcome of project diffusing to other field.

\subsection{Innovation Clustering Network}

Three cases show that all innovation subjects implement innovation clustering as a complex project, which forming a temporary network and a complex system see in Figure 1. In this system, government play as a guarantor on national strategy and policy, universities and colleges and R\&D work as innovation source in innovation clustering to providing innovation resources and diffusing innovation knowledge, peer enterprises and supporting enterprises act as cooperator to involving innovation activities.

As the leader and organizer of the innovation clustering activities, dominant firm directly connect with other innovation subjects and indirectly promote the interactive 
innovation between other subjects, who guide innovation clustering of whole system.

\subsection{Innovation Clustering Capability}

Based on case analysis, we found that the innovation clustering capability of three dominant firms manifested as anti-risk ability, technology innovation ability, resource integration ability, technology diffusion ability, income distribution ability and boundary management ability as Figure 2 shows. The first two ability focus on the internal inno-

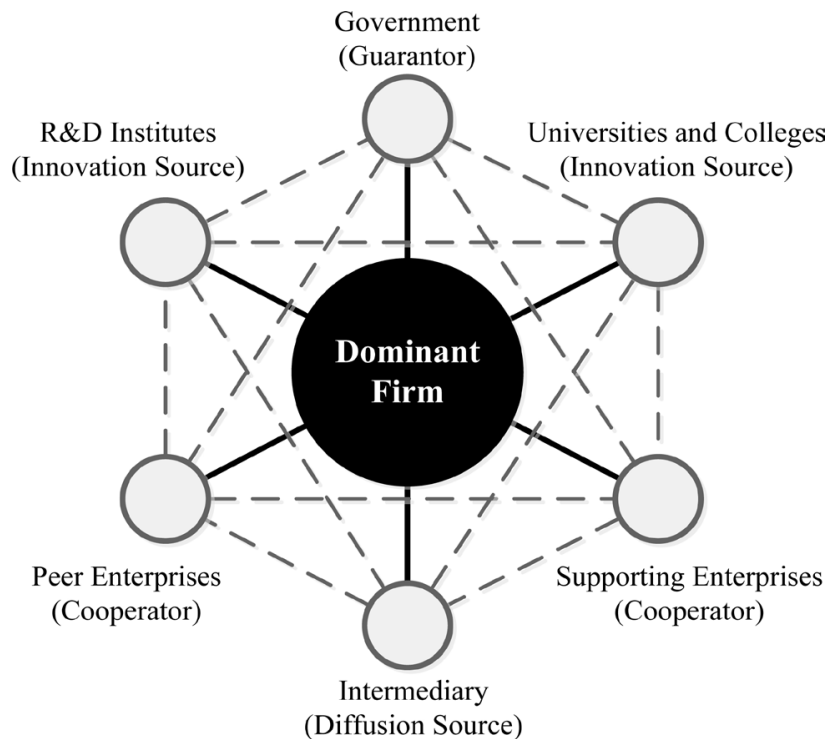

Figure 1. Innovation system in innovation clustering.

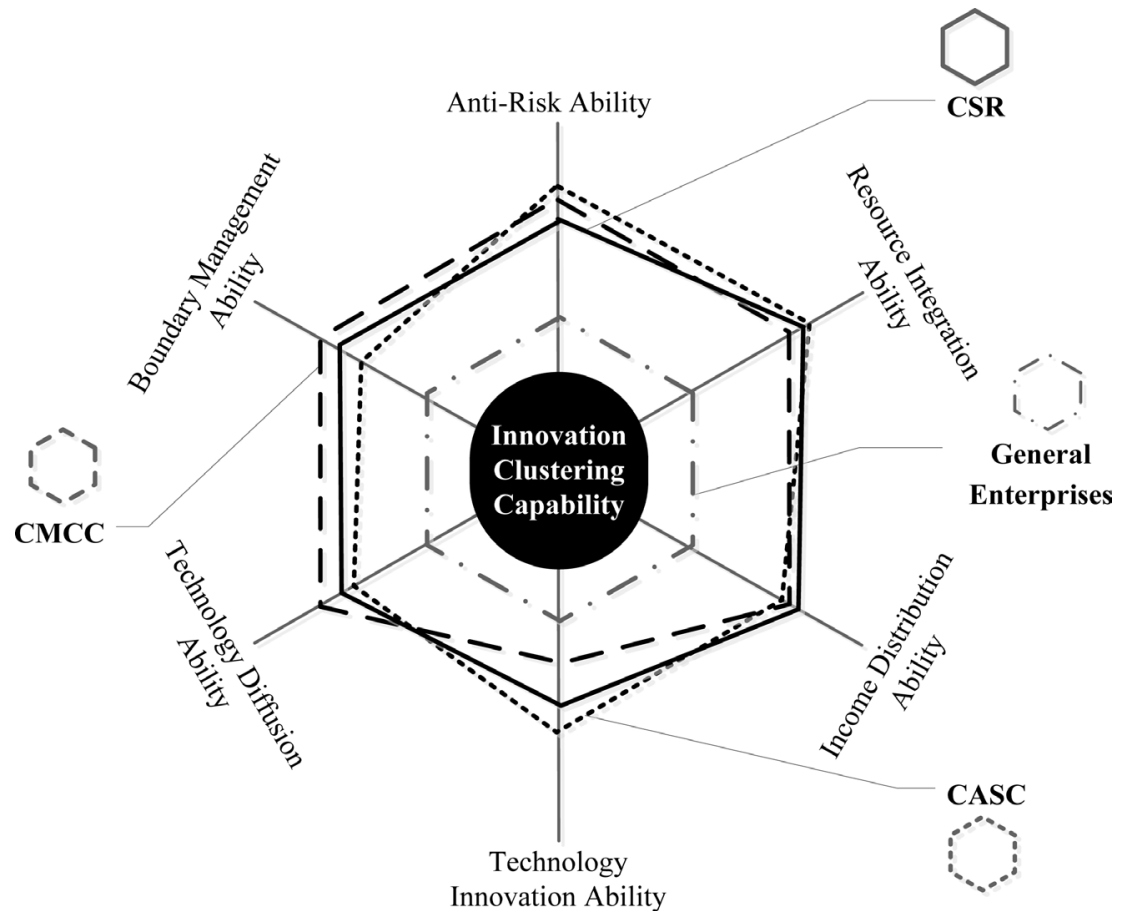

Figure 2. Multidimensional innovation clustering capacity model. 
vation ability of dominant firm, others emphasis external organizing ability. Prior to general enterprises, dominant firm from national innovation system has absolute advantage in all ability dimensions. Meanwhile, dominant firm in three cases show some difference with each other. CASC place emphasis on integration of internal innovation resources, CMCC focus on external integration and CSR intend to achieving synergies of both. Three firms have significant difference on their technology innovation ability, technology diffusion ability and innovation boundary management ability, which will be the core capability for innovation clustering.

\subsection{Knowledge Integration Process}

As shown in Figure 3, the process of innovation clustering in essence is a knowledge integration process cross organization, which is based on a complex project. The process of innovation clustering involves process of resource clustering, innovation implement, innovation standardization and innovation diffusion. The process was accompanied by the input of innovation clustering capability and the management of knowledge. Separately, the first process is resource clustering in which the dominant firm use its resource integration ability and boundary management ability to gather different kinds of innovation resource for the knowledge integration strategy. In this phase, all resources forming a resource pool and knowledge pool which established the basic conditions to accessing innovation knowledge for innovation clustering.

The second process is the innovation implement process in which dominant firm utilize its anti-risk ability, technology innovation ability and resource integration ability

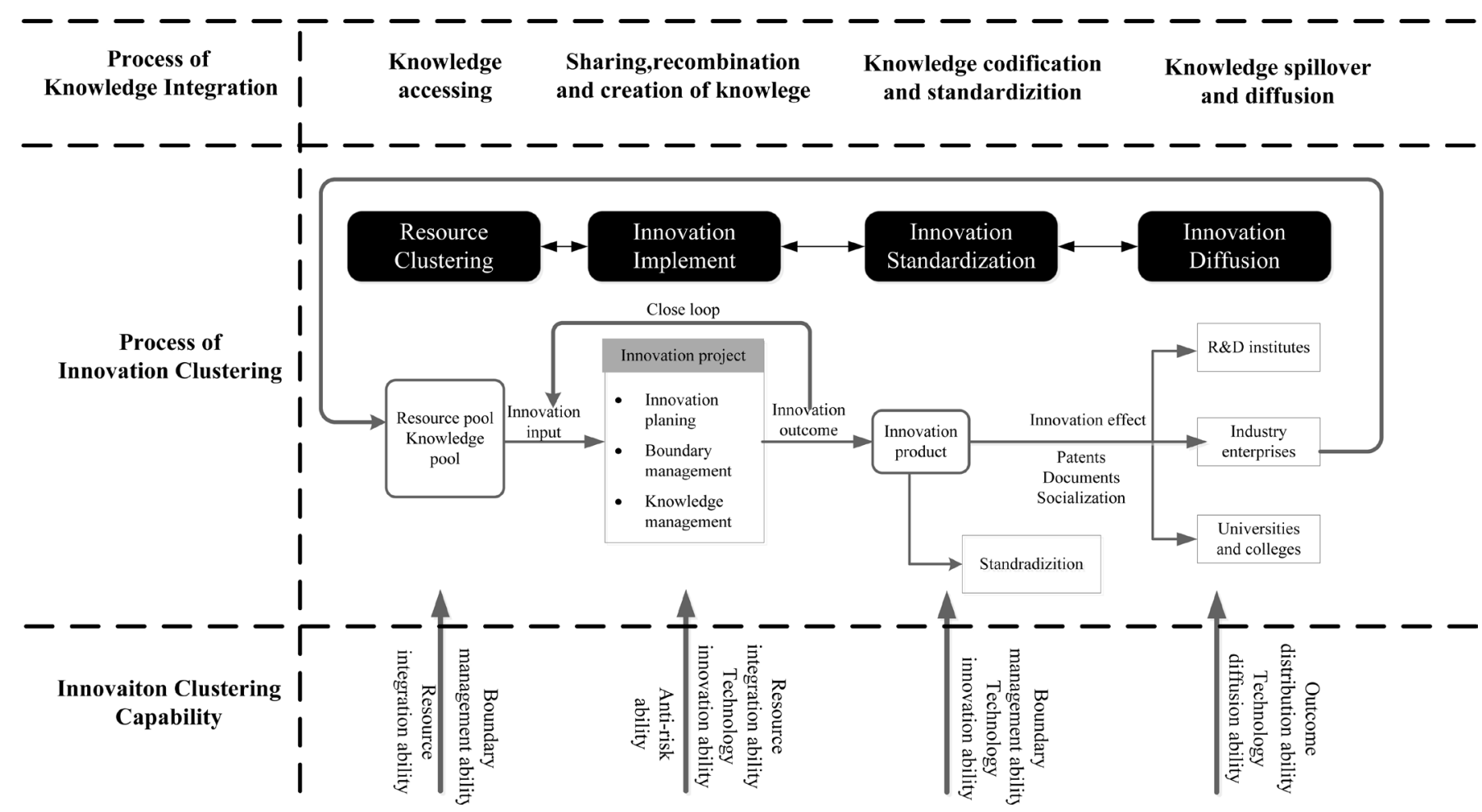

Figure 3. The interacting mechanism model of innovation clustering capacity of big state-owned companies. 
to organize and manage the innovation process. The innovation planning and systematic innovation management system provides innovation clustering a framework of knowledge integration, which promotes sharing, recombination, creation of innovation knowledge. The innovation input and outcome also presented as a close loop of innovation value chain, which guaranteed the efficiency of knowledge flow.

The third process is the management of innovative product, which need the technology innovation ability and boundary management ability to strengthen the possibility of successive application of innovative product. The codification and standardization of innovative knowledge will optimize knowledge structure and facilitate knowledge integration.

The last process is innovation diffusion which related to spread of innovation effect. All innovation subjects will be mobilized to promote technology spill over and knowledge spill over. The knowledge integrated from innovation implement will also be transferred and absorbed to all subjects in the innovation system, and the capability of whole system will be promoted after each element enhanced. Thus the integration of knowledge is the core concern and determinant of innovation clustering.

\section{Conclusions and Limitation}

This paper conceives the innovation clustering process as a knowledge integration process to explore the internal mechanisms of dominant firm-centered innovation cluster. We identified six dimensions of innovation clustering capabilities of dominant firm based on the theory of core enterprise of innovation network, and found that the innovation capabilities of dominant firm were the important antecedent variables of the performance of innovation clustering. In three cases, the innovation clustering capability shows some differences in sub-dimensions, which provides a holistic perspective to explain the constitution of innovation clustering capability. Compared with general enterprise, dominant firm in three cases has comparative advantages which should gain more attention from government to promote the operation of national innovation system.

Centering on the process on innovation clustering, this paper uses case analysis to induce the specific phase of innovation clustering project and combs the input and output of each phase. Because of the essence of knowledge of innovation, we also match the process of innovation clustering with the process of knowledge integration. As the source of innovation, innovation knowledge has been collected, accessed, shared, transferred, integrated and created for the target of innovation. This paper established a model of innovation clustering with innovation clustering capability and knowledge integration, which suggests that the highly matched capability and the process knowledge integration are the core guarantee of innovation clustering.

As the leader and the organizer of national innovation cluster, dominant firm from the national innovation system needs to foster, accumulate and use its innovation clustering capability to form the basic conditions. On that basis, dominant firm can reduce innovation cost by using the mechanism of economy of scale and resource integration, 
and reduce risks by internal transaction and national innovation projects. Moreover, they can enhance innovation efficiency through mechanism of innovation network connection, and promote innovation diffusion by mechanism of learning and sharing and knowledge spillover. Drove by the innovation from value chain, technology chain and industry chain of the dominant firm, the national innovation system will develop and evolve in a better direction.

The limitation of this paper is that the sample of case study is all state-own enterprise and the conclusion is proper to this type of enterprise, which remains insufficient to explain general enterprise. And the model is established in the context of China. Further study can be implemented in other contexts to compare the difference. Because this is a qualitative research, it's also worth carrying out an empirical study to examine the results of this study in further research.

\section{Acknowledgements}

The authors gratefully acknowledge the contributions of Zhen $\mathrm{Ma}, \mathrm{Yu} \mathrm{Lu}$ and the support of CASC, CMCC, CSR.

\section{References}

[1] De Bresson, C. (1989) Breeding Innovation Clusters: A Source of Dynamic Development. World Development, 1, 1-16. https:/doi.org/10.1016/0305-750X(89)90218-0

[2] OECD (1999) Boosting Innovation: The Cluster Approach. OECD, Paris.

[3] Zhang, L.H. and Lin, S.L. (2010) Research on the Correlation between Innovation Agglomeration and Industrial Agglomeration. Study in Science of Science, 4, 635-640.

[4] Liu, L.J. and Si, C.L. (2009) A Review of 17-Year Research Literature on Innovation Network. Chinese R\&D Management, 4, 68-77.

[5] Dang, X.H. and Zheng, D.P. (2011) A Further Review on "A Review of 17-Year Research Literature on Innovation Network". Chinese R\&D Management, 3, 9-15.

[6] Xu, Q.R. (2010) Research, Development and Management of Technological Innovation. Higher Education Press, Beijing.

[7] Lundvall, B.A. (1992) National Systems of Innovation: Towards a Theory of Innovation and Interactive Learning. Pinter Publishers, London.

[8] Gray, D.O. (2011) Cross-Sector Research Collaboration in the USA: A National Innovation System Perspective. Science and Public Policy, 2, 123-133. https:/doi.org/10.3152/030234211X12960315267417

[9] Feng, Z.J. (1999) The Improvement and Development of China's National Innovation System. China Soft Science Magazine, 1, 55-58.

[10] Carbonara, N. (2004) Innovation Processes within Geographical Clusters: A Cognitive Approach. Technovation, 1, 17-28. https:/doi.org/10.1016/S0166-4972(02)00046-9

[11] Boer, H., Kuhn, J. and Gertsen, F. (2006) Continuous Innovation Managing Dualities through Coordination. CINet Working Paper Series.

[12] Hekkert, M.P., Suurs, R.A.A., Negro, S.O., et al. (2007) Functions of Innovation Systems: A New Approach for Analyzing Technological Change. Technological Forecasting and Social Change, 4, 413-432. https:/doi.org/10.1016/j.techfore.2006.03.002

[13] Nonaka, I. (2010) Redundant, Overlapping Organization: A Japanese Approach to Manag- 
ing the Innovation Process. California Management Review, 3, 27-38.

[14] Clark, K.B. and Fujimoto, T. (1991) Product Development Performance. Harvard Business School Press, Boston.

[15] Janczak, S. (2004) How Middle Managers Integrate Knowledge within Projects. Knowledge and Process Management, 3, 210-224. https:/doi.org/10.1002/kpm.207

[16] Warglien, M. (1990) Innovazione e Impresa Evolutiva. CEDAM, Padova.

[17] Dosi, G. (1988) Sources, Procedures, and Microeconomic Effects of Innovation. Journal of economic literature, 3, 1120-1171.

[18] Coombs, R. and Hull, R. (1998) Knowledge Management Practices' and Path-Dependency in Innovation. Research Policy, 3, 237-253. https:/doi.org/10.1016/S0048-7333(98)00036-5

[19] Nonaka, I. and Takeuchi, H. (1995) The Knowledge-Creating Company: How Japanese Companies Create the Dynamics of Innovation. Harvard Business School Press, New York.

[20] Hislop, D. (2003) Knowledge Integration Processes and the Appropriation of Innovations. European Journal of Innovation Management, 3, 159-172. https:/doi.org/10.1108/14601060310486235

[21] Fleming, L. (2001) Recombinant Uncertainty in Technological Search. Management science, 1, 117-132. https:/doi.org/10.1287/mnsc.47.1.117.10671

[22] Badii, A. and Sharif, A. (2010) Information Management and Knowledge Integration for Enterprise Innovation. Logistics Information Management, 2, 145-155.

[23] Yin, R.K. (2003) Applications of Case Study Research. Sage Publications, Thousand Oakes.

[24] Eisenhardt, K.M. (1989) Building Theories from Case Study Research. Academy of Management Review, 4, 532-550.

\section{Submit or recommend next manuscript to SCIRP and we will provide best service for you:}

Accepting pre-submission inquiries through Email, Facebook, LinkedIn, Twitter, etc.

A wide selection of journals (inclusive of 9 subjects, more than 200 journals)

Providing 24-hour high-quality service

User-friendly online submission system

Fair and swift peer-review system

Efficient typesetting and proofreading procedure

Display of the result of downloads and visits, as well as the number of cited articles

Maximum dissemination of your research work

Submit your manuscript at: http://papersubmission.scirp.org/

Or contact jss@scirp.org 